\title{
The relationship between low-intensity exercise and psychological distress among college students
}

\section{SUMMARY}

OBJECTIVE: The purpose of our study was to confirm the relationship between low-intensity exercise and physical and mental health status among college students in China.

METHODS: This was a school-based cross-sectional study. The physical and mental health status was measured using a 12-item general health questionnaire(GHQ12) and low-intensity exercise was recorded by a self-reporting questionnaire.

RESULTS: The results revealed that the score of the GHQ12 was inversely associated with a higher frequency of low-intensity exercise $(r=-0.38, p=0.001)$.

CONCLUSIONS: Our study suggests that low-intensity exercise may be a proper mean for improving the physical and mental health status of college students. School departments should take measures to push students to take part in physical activity.

KEYWORDS: Cross-sectional studies. Mental health. Motor activity. Exercise. Students.

\section{INTRODUCTION}

In recent decades, the number of adolescents and young adults with poor mental health has increased, especially among college students ${ }^{1}$. In the meantime, the prevalence of medical and nonmedical uses of psychiatric medication among undergraduate students is still high. A study found that individuals who engage in regular physical activity have lower levels of anxiety ${ }^{2}$ and higher quality of life than patients with advanced chronic kidney disease ${ }^{3}$. Engagement in physical activity can be an important contributing factor in the mental health of undergraduate students ${ }^{4}$.
We hypothesize that the relationship between low-intensity exercise and physical and mental health status among college students in China still exists. However, little is known on whether low-intensity exercise has a positive effect on the mental health status of college students in China.

The aim of this study was to confirm the relationship between low-intensity exercise and the physical and mental health status among college students in China to offer a basis for the prevention of poor physical and mental health status among college students. 


\section{METHODS}

\section{Subjects}

Data collection was performed in a school to obtain information on low-intensity exercise and the physical and mental health status of college students. A total of 1287 students (452 males and 832 females) aged from 18 to 20 years old were included in the study. Personal information and written informed consent were obtained from all the subjects.

Measurement of physical and mental health status(psychological distress)

The physical and mental health status was measured using a 12-item general health questionnaire (GHQ-12) ${ }^{5}$. The GHQ-12 questionnaire contained twelve items, with four possible answers each: "Better than usual=0", "Same as usual=1", "Worse than usual=2", and "Much worse than usual=3". The GHQ-12 score was calculated based on the score of each item. The higher the total score of the GHQ12 , the worse the physical and mental health status of students.

\section{Measurement of low-intensity exercise}

Low-intensity exercise was defined as at least 20 minutes, once a day, of activities such as walking or shadowbox. Then the frequency of low-intensity exercise in a week was calculated.

\section{Statistics analysis}

Data were analyzed using the SPSS20.0 software (SPSS Inc, II, Chicago, IL, USA). Description statistics were used for the frequency of gender. The distribution of the GHQ-12 score and the frequency of daily low-intensity exercise and line chart was drawn. The Pearson correlation analysis was performed to explore the relationship between the GHQ-12 score and the frequency of daily low-intensity exercise. A P-value of less than 0.05 was considered as statistically significant.

\section{RESULTS}

A total of 1287 students (452 for males and 832 for females) aged from 18 to 20 years old were included in the study. We first explored the distribution of the GHQ-12 score and the frequency of daily low-intensity exercise. The Normal distribution of the GHQ-12 score and the frequency of daily low-intensity exercise were observed in the present study (Figure 1 and Figure 2).
Then, we explored whether the frequency of daily low-intensity exercise was associated with the GHQ-12 score. Figure 3 shows that the GHQ-12 score decreases with a higher frequency of daily low-intensity exercise. The Pearson correlation analysis also found that the score of GHQ12 was inversely associated with a higher frequency of low-intensity exercise $(r=-0.38, p=0.001)$.

\section{DISCUSSION}

The main finding of this study was that the GHQ12 score decreased with a higher frequency of daily low-intensity exercise. The results of the present study further confirmed the results of a previous study and were higher than the results from a meta-analysis in China $^{6}$. It has also been found that physical activity

\section{FIGURE 1. DISTRIBUTION OF THE GHQ12 SCORE IN} COLLEGE STUDENTS

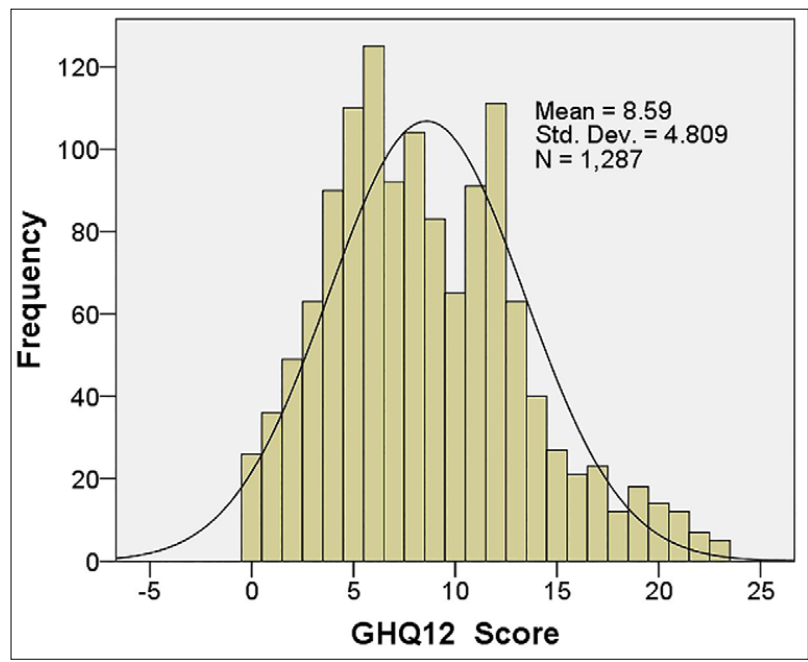

FIGURE 2. DISTRIBUTION OF THE TIMES OF LOWINTENSITY EXERCISE EVERY WEEK IN COLLEGE STUDENTS

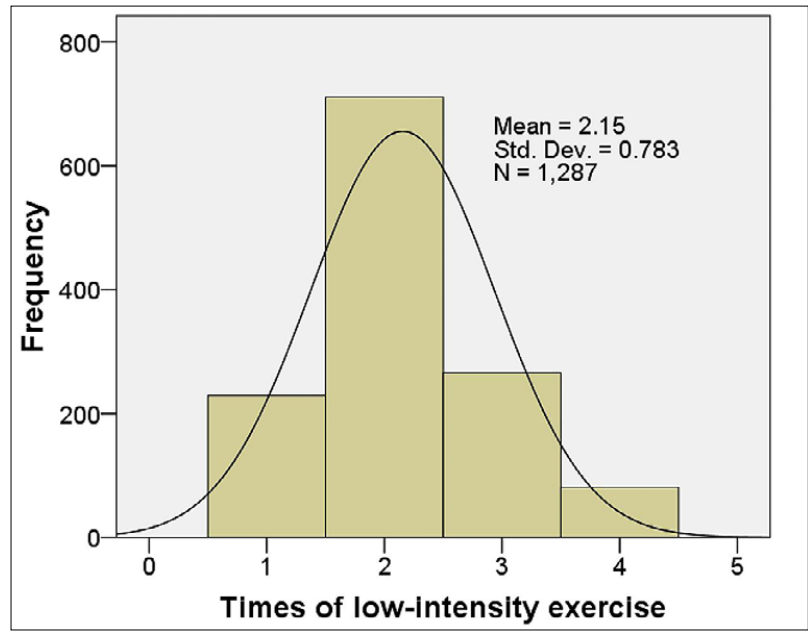


FIGURE 3. LINE TREND OF THE GHQ12 MEAN SCORE WITH THE TIMES OF LOW-INTENSITY EXERCISE

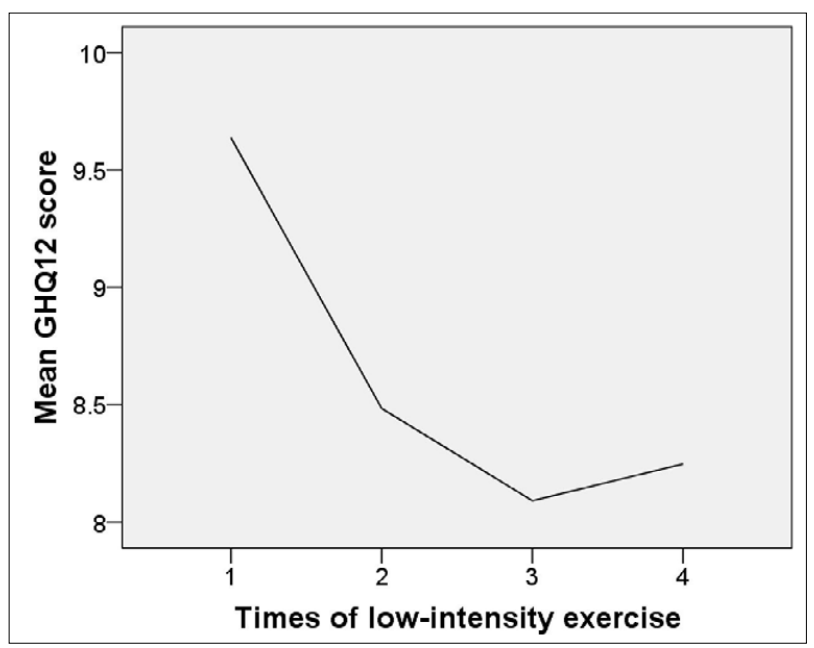

can improve the mental health of older populations ${ }^{7}$.

Some limitations should be addressed in this work. The small sample size of the study is limited are requires further exploration of the risks of a poor physical and mental health status among college students. Additionally, a cross-section study cannot explain the cause-results relationship between low-intensity exercise and physical and mental health status. Although some shortcomings exist, the results of our work offer a direction for future studies.

\section{CONCLUSIONS}

Our study suggests that low-intensity exercise may be a proper mean for improving the physical and mental health status of college students. School departments should take measures to push students to take part in physical activity.

\section{Acknowledgment}

The study was supported by the ministry of education, humanities, and social sciences, research youth project support in 2015 (No.15yjc890050).

\section{Conflict of interest}

The authors declare no conflicts of interest.

\section{Informed Consent}

Informed Consent was obtained from all participants included in the study.

\section{Author Contributions}

Conceptualization, Ergang Zhu; formal analysis, Jun Sun; writing - original draft preparation, Ergang Zhu; writing - review and editing, Tianhua Du; supervision, Jun Sun; funding acquisition, Tianhua Du.

\section{RESUMO}

OBJETIVO: O objetivo do nosso estudo foi confirmar a relação entre o exercício de baixa intensidade e o estado de saúde física e mental entre estudantes universitários na China.

MÉTODOS: Estudo transversal com base na escola foi realizado neste estudo. O estado de saúde física e mental foi medido recorrendo-se a questionários gerais de saúde (GHQ12); exercícios de baixa intensidade foram coletados por questionários de autorrelato.

RESULTADOS: Os resultados revelaram que a pontuação do GHQ12 foi inversamente associada com maior frequência de exercícios de baixa intensidade $(r=-0,38, p=0,001)$.

CONCLUSÕES: Nosso estudo sugeriu que o exercício de baixa intensidade pode ser um meio adequado para melhorar o estado físico e mental dos estudantes universitários. O departamento relacionado à escola deve tomar alguma medida para forçar os alunos a participar da atividade física.

PALAVRAS-CHAVE: Estudos transversais. Saúde mental. Atividade motora. Exercício. Estudantes.

\section{REFERENCES}

1. Chow SKY, Choi EKY. Assessing the mental health, physical activity levels, and resilience of today's junior college students in self-financing institutions. Int J Environ Res Public Health. 2019;16(17). doi: 10.3390/ijerph16173210.

2. Alves DGL, Rocha SG, Andrade EV, Mendes AZ, Cunha ÂG). The positive impact of physical activity on the reduction of anxiety scores: a pilot study. Rev Assoc Med Bras (1992). 2019;65(3):434-40.

3. Calvo-Lobo C, Neyra-Bohorquez PP, Seco-Calvo J. Aerobic exercise effects in renal function and quality of life of patients with advanced chronic kidney disease. Rev Assoc Med Bras (1992). 2019;65(5):657-62.

4. Tyson P, Wilson K, Crone D, Brailsford R, Laws K. Physical activity and mental health in a student population. J Ment Health. 2010;19(6):492-9.
5. Guan M, Han B. Factor structures of General Health Questionnaire-12 within the number of kins among the rural residents in China. Front Psychol. 2019;10:1774.

6. Zeng W, Chen R, Wang X, Zhang Q, Deng W. Prevalence of mental health problems among medical students in China: a meta-analysis. Medicine (Baltimore). 2019;98(18):e15337.

7. Ponce J, Latín C, Leiva V, Cortés G, Rodríguez F, Jiménez CE. Non-pharmacological motor-cognitive treatment to improve the mental health of elderly adults. Rev Assoc Med Bras (1992). 2019;65(3):394-403. 